From the Editors

\title{
De Ethica.
}

\section{A Journal of Philosophical, Theological and Applied}

\section{Ethics}

Welcome to the first issue of De Ethica. It is our hope that De Ethica will find a special niche for itself as a European-initiated project treating a diversity of ethical issues and open to contributions from authors in all parts of the world. We hope this focus will have wide appeal but we take nothing for granted. At an early stage in the evolution of the project, we asked the important question: Is there room for another ethics journal? As work proceeded on the development of the idea of a journal with a triple focus, it became clear that, as far as De Ethica is concerned, the answer to that question is 'yes'. There are a number of reasons for this but the first of these must be its close connection to Societas Ethica with its 50-year history as a Society for Ethical Research with a multi-national and multilingual membership. This connection brings with it a distinctive approach and tradition which De Ethica will be proud to follow: a broad tolerance and understanding of the variety of philosophical and religious traditions reflected in that membership. As for its distinctively triple focus, there are few, if any, journals explicitly dedicated to philosophical, theological, and applied ethics and this in itself should attract some fresh and interesting submissions.

But the journal has other distinctive features of a more direct and practical kind. De Ethica will be an Open Access journal operating on a non-profit-making basis. Its contributors will also have the assurance that their article will be vigorously peerreviewed and that, while we had to recognize with regret that it would not be feasible to adopt the Societas tradition of a bilingual or multilingual approach, we will seek to adopt a sympathetic approach to submissions from those whose first language is not English. Finally, De Ethica will, from its foundation, have a special interest in what is now called practical or applied ethics - the analysis and discussion of issues for decision in the real world, from human relationships to environmental ethics and climate change.

So we can answer that original question 'Is there room for De Ethica?' with a firm yes. De Ethica is indeed a journal capable of filling an important gap and we would like to thank those who have shown their support for the project including, in particular, the Swedish Research Council and Linköping University Electronic Press.

In setting out our aspirations for the new journal we would like to make it clear that, while we welcome submissions from all philosophical and theological traditions, we will seek to encourage work that advances an original thesis and a clear and concise argument. While this is important for all three areas, we regard this element as fundamental, not only from the point of view of philosophy, both theoretical and applied, 
but also in the discussion of religious topics. The inclusion of religious perspectives on ethics implied by the journal's title is especially important at the present time in that philosophy and religion are currently often seen as rivals in universities in the Englishspeaking world. Indeed, it is fashionable at the moment for leading philosophers to loudly advertise their atheism or secularism. Nevertheless, most ordinary people continue to see these two areas of human thought as close.

If we were to ask when philosophy and theology were last in philosophical harmony with each other, we might need to look back to the mid-twentieth century and the kind of practical philosophy favoured by philosophers such as the Scottish philosopher John Macmurray or the Danish philosopher Knud Løgstrup, author of The Ethical Demand (1956). Although sometimes described as Christian Socialism, this tendency is better not seen in political or even religious terms, but rather as pioneering the late twentieth century move to applied ethics.

As this implies, there is every reason to regard applied ethics as a continuing tradition with a much longer pre-history than it is usually given credit for. But there can be little doubt that, as we understand it today, applied ethics, especially bioethics, has made a special and distinctive contribution to the landscape of philosophical thinking in the twentieth century, and that it, together with the broader conception, applied philosophy, has changed public perceptions of the task of philosophy in the twenty-first. The latter part of the twentieth century brought a mindset more sympathetic to philosophical engagement with practical problems. It also saw a marked retreat from abstruse metaphysical philosophy and a wish to see complex ideas put forward in language that can be readily understood. On the negative side, however, it has become associated in some minds with forms of postmodernism that have created new versions of abstruse philosophy and an invasion of political correctness that has brought with it a new threat of enforced conformism.

Perhaps pressures like these are inevitable when practical issues are increasingly occupying the philosophical stage. Today's world is plagued by many of the age-old problems of crime and violence but it also faces new threats and new weapons of mass destruction. At the same time, the moral consensus on which we could in the past rely is rapidly eroding. Of course, for some of the problems confronting us, such as the planetary and environmental concerns that provide the focus of the first issue of $D e$ Ethica, we may hope that science and technology may be able to provide some solutions. But technology is not enough. We need normative as well as practical expertise, combined with the defining feature of true philosophy - a willingness to follow an argument where it leads. And for this we need scope for thoughtful discussion something beyond the brief and fragmented opportunities offered by articles in the national press and other media outlets.

In launching this journal, then, we hope to provide a platform for philosophically reflective articles that address the problems of the day. We hope that, while publication has become a necessary end in itself for academics, the unique combination of its European and international status will attract submissions for De Ethica from people whose goals are broader than this, who do genuinely have something to say, and who are capable of ignoring outside pressures and giving their time and energy only to what they believe is truly important and worthwhile.

Applied philosophy is faced by a particular challenge because it requires people to struggle with new and untried issues - often areas where technology has moved ahead of human experience and in which there is no history to draw on. We hope that we will 
find authors who recognise this and tread carefully in areas where mistakes in reasoning can have unprecedented practical impact. The background assumption for those who venture to tread in these difficult areas must be that despite the inevitability of change and the unavoidably shifting concerns of the present day, we still need to ask those traditional questions: What makes a good life? And what kind of society is most likely to make that good life possible?

Brenda Almond, Editor in Chief

Publication made possible by generous support from the Swedish Research Council. 